\title{
PROACTIVE RISK ASSESSMENT OF VINCRISTINE USE PROCESS IN A TEACHING AND REFERRAL HOSPITAL IN KENYA and the implications
}

\author{
Emmanuel Kipkurui Kurgat ${ }^{1,2}$, Irene Weru,2, David Wata1,2, *Brian Godman,4,5, Amanj Kurdi ${ }^{3,6}$, \\ Anastasia N Guantai ${ }^{1}$ \\ 1School of Pharmacy, University of Nairobi, P.O Box 19676-00202 Nairobi, Kenya. Emails: \\ manuhkurui@yahoo.com; weru@knh.or.ke; dwata@knh.or.ke; dean-pharmacy@uonbi.ac.ke \\ ${ }^{2}$ Kenyatta National Hospital, P. O Box 20723-00202, Nairobi, Kenya, \\ ${ }^{3}$ Strathclyde Institute of Pharmacy and Biomedical Sciences, Strathclyde University, Glasgow, UK \\ Email: brian.godman@strath.ac.uk; amani.baker@strath.ac.uk \\ ${ }^{4}$ Division of Clinical Pharmacology, Karolinska Institute, Stockholm, Sweden. Email: \\ Brian.Godman@ki.se \\ 5School of Pharmacy, Sefako Makgatho Health Sciences University, Garankuwa, Pretoria, South \\ Africa \\ ${ }^{6}$ Department of Pharmacology, College of Pharmacy, Hawler Medical University, Erbil, Iraq.
}

${ }^{*}$ Author for correspondence: Strathclyde Institute of Pharmacy and Biomedical Sciences, University of Strathclyde, Glasgow G4 0RE, United Kingdom. Email: brian.godman@strath.ac.uk. Telephone: 0141548 3825. Fax: 01415522562 and Division of Clinical Pharmacology, Karolinska Institute, Karolinska University Hospital Huddinge, SE-141 86, Stockholm, Sweden. Email:

Brian.Godman@ki.se. Telephone + 46858581068 . Fax + 46859581070

(Accepted for publication Journal of Oncology Pharmacy Practice)

ABSTRACT

Introduction: The chemotherapy use process is potentially risky for cancer patients. Vincristine, a "High Alert" medicine, has been associated with fatal but preventable medication errors. There is a need to improve the use of vincristine especially in lower and middle income countries with constraints with resources and adequate approaches to the administration of cancer medicines; however a rising prevalence of cancer cases. These concerns can be addressed by performing proactive risk assessments using Healthcare Failure Mode Effect Analysis (HFMEA) and implementing the findings. Methods: A multidisciplinary health team driven by pharmacists identified and evaluated potential failure modes based on a vincristine use process flow diagram using a hazard scoring matrix in a leading referral hospital in Kenya. Results: The processes evaluated were: prescribing, preparation and dispensing, transportation and storage, administration and monitoring of the use of vincristine. 77 failure modes were identified over the 3 month study period, of which 25 were classified as high risk. Thirteen were adequately covered by existing control measures while 12 including one combined mode required new strategies. Two of the failure modes were single-point weaknesses. Recommendations were subsequently made for improving the administration of vincristine. Conclusions: HFMEA is a useful tool to identify improvements to medication safety and reduction of patient harm. The HFMEA process brings together the multidisciplinary team involved in patient care in actively identifying potential failure modes and owning the recommendations made, which are now being actively followed up in this hospital. Pharmacists are a key part of this process.

Key words: Cancer, Vincristine, Processes, Healthcare failure mode effect analysis (HFMEA), Hospitals, Kenya

\section{BACKGROUND}

The chemotherapy use process is considered as potentially risky for cancer patients due to its complexity, use of medicines with narrow therapeutic indices, multiple drug use and use of potentially toxic compounds $(1,2)$. Medication errors can occur at any phase of the medication use process from prescription, preparation, dispensing, and administration to the monitoring of patients. The medication use process typically involves a multidisciplinary approach with physicians, pharmacists and nurses performing various roles (3).

Medication errors lead to an increase in healthcare costs and diminish patient confidence in the healthcare system. Furthermore, they contribute to significant morbidity and mortality of hospitalized patients $(2,4)$. According to the Institute of Medicines (IOM) report, it is estimated that between 44,000 to 98, 000 patients in America die yearly as a result of medication errors, which can be 
avoided. This is more than mortalities from automobile accidents, breast cancer or AIDS, and costs approximately US $\$ 29$ billion annually $(5,6)$.

Medication errors involving antineoplastic agents may potentially be catastrophic for patients because of their toxicity and the poor health status of many cancer patients $(7,8)$. However, unfortunately these are not uncommon. In a study in Spain, medication errors were reported among $17.2 \%$ of patients on chemotherapy (9). The detected errors were stratified according to the process of use into prescriptions $(75.7 \%)$, preparation $(21 \%)$, dispensing $(1.8 \%)$, administration $(1.1 \%)$ and monitoring (0.4\%) (9). In 2003, the Institute for Safe Medication Practices reported that cancer chemotherapy topped the list of high-alert medications, higher than intravenous potassium chloride and insulin as potential threats to patient safety (10). Consequently, it is an important area to concentrate on. This is particularly the case in lower and middle income countries (LMICs), with LMICs currently accounting for approximately $57 \%$ of cancer cases worldwide and up to $70 \%$ of cancer deaths (11-14). In addition, affordability of cancer care is a key issue in LMICs and available resources and treatments must be carefully managed (15).

Similar to the global trends, there is an increase in the number of cancer cases in Kenya which in turn has the potential to predispose many patients to the harmful effects of chemotherapeutic agents including vincristine $(15,16)$. According to a study in Kenyatta National Hospital $(\mathrm{KNH})$, Nairobi, by Kurgat et al (17), vincristine was administered to $4 \%$ and $36 \%$ of patients treated in an out-patient oncology clinic and in-patient wards respectively for their cancers. Vincristine is listed as one of the high alert medicines (HAMs) by various patient safety organizations including the Institute of Safe Medication Practices (ISMP), the Australian Commission on Safety and Quality in Healthcare (ACSQHC), the National Patient Safety Agency (NPSA) and the Joint Commission on Accreditation of Healthcare Organizations $(\mathrm{JCAHO})(8,18,19)$. The risk of medication errors are high with vincristine due to its low therapeutic index and increasing usage (20). Medication errors associated with vincristine, especially inadvertent intrathecal administration, have a greater potential to cause harm and fatal outcomes (21); consequently care is needed with its administration. In 2015, it is believed that there were 120 reported cases of inadvertent intrathecal administration of vincristine worldwide with 32 documented in the English language of which 25 were fatal (22). Unfortunately, many other cases have gone unrecognised or unreported adding to the concerns with the prescribing and administration of vincristine $(22,23)$.

The prescribing of vincristine and vincristine-based chemotherapy at KNH is typically undertaken by medical officers on specialisation training (senior house officers) under supervision of medical specialists. This is the practice in many teaching and referral hospitals worldwide (24-26). Currently at $\mathrm{KNH}$, there is no formal induction training program for new healthcare professionals on the safe use of cytotoxics, no register of authorized physicians than can prescribe chemotherapy, or regular competency assessments. This is a concern given key issues surrounding the administration of cytotoxics. There is also currently no standard protocol for cancer management and the safe use of chemotherapeutic agents in $\mathrm{KNH}$ or other hospitals in Kenya dealing with cancer patients.

Prescriptions are typically handwritten onto a specially designed oncology treatment sheet, with again the potential for errors. In addition, ordering of medicines is usually undertaken by nurses in $\mathrm{KNH}$ by duplicating the prescription onto a requisitioning form (S11) and non-schedule form for in-patients, while for out-patients the prescription will suffice. This can again lead to errors.

Dispensing of vincristine and other cytotoxics is currently undertaken by pharmacists and pharmaceutical technologists at $\mathrm{KNH}$ under the supervision of oncology pharmacists. There is currently a centralised system of dispensing anticancer medications, with the pharmacy serving both out- and in-patients. Verification of medication orders and prescriptions are performed before dispensing medicines against the existing protocols and patient's medical records to help reduce errors. However, mislabelling or lack of labels have been noted as risk factors for medication errors in chemotherapy $(22,27)$. Consequently, improvements can potentially be made in this area in $\mathrm{KNH}$.

The chemotherapy medications in $\mathrm{KNH}$ are usually collected by the nurse who verifies the medicines against the requisition form; subsequently, transports them for administration (out-patient) and storage (in-patient) awaiting administration. Vincristine in $\mathrm{KNH}$ is the either dispensed in vials for preparation or in small-volume syringes for administration with other medications including intrathecal drugs. Preparation of vincristine is currently undertaken in two areas in $\mathrm{KNH}$. There is a dedicated chemotherapy preparation room adjacent to oncology pharmacy manned by pharmacists and pharmaceutical technologists. However, due to inadequate pharmacy staff and high workloads, preparation is also currently undertaken in the procedure rooms in the wards by senior house officers. 
In the procedure rooms, there is currently no provision for independent double checks given that preparation and administration procedures are performed by the same senior house officers.

The current production environment also does not fully guarantee the safety of staff involved in the preparation of vincristine and the sterility of the final product. The current facilities lack biological safety cabinets, adequate personal protective equipment, orderly and logical positioning of equipment or material, and is prone to interruptions by inpatients. Medication spillage is also a major concern as antineoplastic agents can cause acute and chronic problems on patients and handlers due to their mutagenic, teratogenic and carcinogenic effects $(28,29)$.

Failure Mode Effect Analysis (FMEA) is one of the techniques used for system improvement to enhance safety (30). FMEA is team-based, proactive, systematic and reasoned-based technique used to prevent process and outcome problems before they happen (31). FMEA has been used in the engineering field to improve quality, safety, reliability of products and reduce potential risks (32). The health sector has adopted a high-risk industry approach to safety and borrowed tools for the same purposes, renamed Healthcare Failure Mode Effect Analysis (HFMEA) $(30,33)$. As a result, HFMEA is now being increasingly used to assess and improve the safety of healthcare processes, including IV drug administration, blood transfusions, and organ transplantations $(30,33,34)$. JCAHO expects health organisations to conduct at least one proactive risk analysis of high-risk processes per year (35).

However, we believe there have been few studies in Kenya that have used the HFMEA approach, and none to improve the use of vincristine. Consequently, this study used Healthcare Failure Mode Effect Analysis (HFMEA) to better understand the risks associated with the vincristine use process in a leading teaching and referral hospital in Kenya since a preliminary audit undertaken at the oncology unit of the hospital revealed a lack of standard cancer treatment protocols and monitoring of processes. This builds on such studies in high income countries (30). The findings will be used to improve the process for vincristine administration in this and other relevant hospitals in Kenya benefitting all key stakeholder groups. It is envisaged the findings and their implications will also be useful to other LMICs where there is increasing use of vincristine.

\section{METHODS}

This study aimed at exploring the threats to patient safety and determining the appropriate medication errors mitigation strategies using the HFMEA method.

\subsection{Study Design and Site}

This study applied a prospective, system-focused clinical risk assessment entitled HFMEA of the Vincristine use process in the out-patient and in-patient oncology units of Kenyatta National Hospital (KNH) between April and June 2017 in the out-patient and in-patient oncology unit. KNH is the largest referral and teaching hospital in Kenya with a 1800 bed capacity located in Nairobi. Consequently, if there are problems in this hospital, they are likely to be similar or greater in other hospitals in Kenya where vincristine is administered.

\subsection{Study Population and Sample Size Determination}

The study population comprised medical officers, pharmacists, pharmaceutical technologist and nurses working at the KNH oncology unit who are primarily involved in the vincristine use process of prescribing, preparation and dispensing, transportation and storage, administration and monitoring. The recommended size for a multidisciplinary team to improve processes is $6-10$ members $(31,33)$.

The multidisciplinary team was assembled according to HFMEA guidelines (31) (Box 1), similar to other countries (30). The team comprised 7 regular members and 2 advisors, the oncology ward paediatrician and the principal oncology pharmacist. The other members were 2 senior house officers in paediatrics and internal medicine, 1 pharmaceutical technologist and 1 pharmacist working in oncology pharmacy, 2 nurses working in the paediatric oncology ward and the adult oncology ward and the principal investigator (EKK), who led the team, participated in the study. Assistance was also provided by the senior personnel in the School of Pharmacy to help drive the process and documentation.

\subsection{HFMEA Procedure}

An assessment of prescribing, preparation and dispensing, transportation, storage, administration and monitoring of vincristine was carried out. 
An introductory meeting was held to take the members through the features of the HFMEA process as well as their roles and responsibilities. A second meeting was held whereby a process flow diagram (Figure 1) adapted from a study by Cheng et al (1) was developed. The principal investigator (EKK) consulted the team members in their respective units to further refine potential processes and subprocesses to improve future use. The investigator requested members to enumerate potential failure modes and causes for each sub-process they are involved in. A third meeting was held whereby members determined the likelihood of potential failure modes occurring, the severity of their effects on patients and processes, and the chances of any failures being detected and intercepted before they occur thereby calculating the hazard score using hazard scoring matrix (Table 1).

A fourth meeting was held to analyse the failure modes together with failure mode causes with a hazard score of 8 or higher, and those that are single point weakness for which further actions were needed, using the HFMEA decision tree. The failure modes and causes were analysed and categorized as eliminate, control or accept. On the fifth meeting, the team made recommendations for each failure mode cause(s) that needed to be controlled or eliminated. There was no particular order to the final identified failure modes. The selected failure modes were identified by the team as currently having inadequate preventive measures in place to help reduce their occurrences after a thorough analysis of all failure modes.

\subsection{Data Management, Quality Assurance and analysis}

The collected data was entered in Epilnfo $®$ version 7 database. The data was then cleaned and validated. Access to the folders containing the data was controlled by a password known only to the researcher. The data was regularly backed up in a flash disk.

The analysis was descriptive. Each failure mode was analysed independently and recommendations were made accordingly.

\subsection{Ethical approval}

Permission to conduct the study was granted by Kenyatta National Hospital/University of Nairobi Ethics and Research Committee (KNH-UoN-ERC) (Reference number KNH-ERC/A/317). The permission to collect data was also granted by the various departments where the study was conducted and registered by KNH Research and Programs Department.

Informed consent and voluntary participation was given by healthcare workers without coercion or incentives. Research assistants were trained on ethical considerations before the commencement of the study.

\section{RESULTS}

Five meetings in total were held lasting on average 1.5 hours each. Due to difficulty in having all team members in one meeting, some meetings were held per department.

\subsection{HFMEA Process Description}

The process was sub-divided into 5 phases: (i) prescribing, (ii) preparation and dispensing, (iii) transportation, (iv) storage, and (v) administration and monitoring. Each process step and sub-step was enumerated and numbered consecutively.

As mentioned, currently in $\mathrm{KNH}$, the prescribing of vincristine is undertaken by medical specialists and senior house officers; dispensing is performed by pharmacists and pharmaceutical technologists; the preparation of medicines is undertaken by pharmaceutical technologists, pharmacists and senior house officers; transportation and storage is undertaken by nurses whilst administration and monitoring of medicines are performed by senior house officers. Preparation is undertaken in the oncology pharmacy preparation room and in-patient procedure rooms. Figure 1 illustrates the vincristine use processes and sub-processes.

Seventy seven failure modes were identified, from which 19 were classified as high risk using a hazard scoring matrix (Table 1). Six other failure modes were identified to be single point weaknesses in the process. For each failure mode, failure mode causes were identified and hazard scores determined. Twelve of the 25 failure modes identified were not adequately covered by existing control measures. Two of these were single point weaknesses. Tables 2 and 3 illustrate the 12 failure modes and failure mode causes determined by the HFMEA team using the decision tree method which were lacking adequate control measures that needed urgent addressing. Recommendations for these 
failure mode causes were subsequently made by the team to mitigate against future failures. Transportation and storage of vincristine were considered as low risk steps by the multidisciplinary team, so were not taken further. Section 3.2 describes the 12 failure modes and ways to address these in more detail.

\subsection{Failure modes and Recommendations}

Failure Mode 1: Out-dated weight and height measures indicated on the treatment sheet It was observed by the HFMEA multi-disciplinary team that majority of the patients especially in the wards do not currently have their latest weight and height measures in their treatment sheets. This has the potential of patients being under or over-dosed. The team recommended an amendment of the chart to provide for space for twice monthly charting of patients' weight and height.

Failure Mode 2: Past history inconclusive in determining last date of administration The current treatment chart does not provide adequate space to indicate the date of administration, which makes it difficult for the prescribers to schedule the next course of treatment. Amendments on the treatment sheet to provide space for including the date and the sensitization of prescribers on the difference between the scheduled day of treatment and the actual date of administration were recommended.

\section{Failure Mode 3: Dose Miscalculation}

Dose calculations by prescribers were considered to be a source of errors which can translate into patients being under- or over-dosed on their medications. Double-checks in the wards and in the pharmacy, as well as the development of job aids with formulas and dose limits, were recommended for adoption.

\section{Failure Mode 4: Obscure prescription/medication order}

The use of handwritten medication orders and dangerous abbreviations were considered as the main causes of obscure orders. The prescribers reported the restrictive size of the medication order on current forms as the cause of using abbreviations. It was recommended that the chart be redesigned to provide adequate space as well as sensitization of staff on agreed abbreviations to help avoid problems. In addition, the possible adoption of a Computerised Physician Order Entry (CPOE) System in chemotherapy prescribing was suggested.

\section{Failure Mode 5-7: Inadequate Labelling}

There was a lack of labels affixed on the medicine bag, vial/box, and syringe, and these were found to be wanting in providing adequate safeguards for the patients in terms of the identity of the chemotherapy medicine and patient, storage conditions, directions of use and warnings. Vincristine being a high-alert medication should have appropriate labels including warnings, which is currently lacking in the unit. The multidisciplinary team recommended that the standard operating procedure (SOP) for handling cytotoxics should be amended to provide for labelling requirements, the procurement of a labelling machine and the development of standard colour-coded labels with clear warning labels.

\section{Failure Mode 8: Medication Spillage}

Medication spillage especially during preparation is a preventable hazard that can cause serious harm to both handlers and patients. Inadequate working spaces both in the pharmacy chemotherapy preparation room and ward procedure rooms, as well as increased workloads, pose a greater risk of this event occurring. Recommendations to address this risk include sensitization or formal induction training of new staff in the various service departments as well as centralizing the preparation of cytotoxics in the pharmacy department. Preparation subsequently undertaken exclusively by pharmacy staff, adequately equipped with Biological safety cabinet/Externally ducted Negative pressure isolators and adequate working benches.

\section{Failure Mode 9: Failure to adequately confirm vital information before administration}

Heavy workload and inadequate staffing level predispose patients to the risk of various errors due to staff burnouts. Proper checks of all aspects (right medication, right patient, right dose, right time, right administration route, right sequence and right administration duration) need to be performed regularly by at least 2 pharmacy staff. Independent bedside double-checks by 2 nurses before administration or by the senior house officers need to be instituted, as well as ensure that medication administration is undertaken by at least 2 staff. These considerations need to be built into a future process plan for vincristine. 
Failure Mode 10a and 10b:

Vincristine leaks to adjacent tissues (Extravasation) (10a)

Veins are some of the most important assets of a patient, which need to be safeguarded (36).

Vincristine is a vesicant medication which can cause tissue burns and necrosis. The team observed

that cancer patients in $\mathrm{KNH}$ were predisposed to extravasation due to the use of peripheral

intravenous access for administration of vincristine and other medicines. Staff sensitization on the

prevention of extravasation, management, and the provision of extravasation kits in all chemotherapy administration areas were recommended. Vincristine dilution in minibags using Sodium chloride $0.9 \%$ should be undertaken to $20 \mathrm{ml}$ for patients aged less than 10 years and $50 \mathrm{ml}$ for patients greater than 10 years old. This is already being enacted as part of the improved process.

The doctor fails to notice exosmosis has occurred (10b)

Post-administration monitoring of patients is vital especially after administering vesicant drugs such as vincristine. The team noted that sometimes due to heavy workload the senior house officers leave the room immediately after medication administration, which could lead to delayed detection of adverse events. It was recommended that chemotherapy administration should be undertaken by at least two staff between 8:30AM and 5:00PM on weekdays so that if there is need for medical specialists' review, specialists can be accessed with ease.

\section{Failure Mode 11: Inadvertent intrathecal administration of vincristine}

Inadvertent intrathecal administration of vincristine has fatal ramifications for patients. The multidisciplinary team assessed the predisposing factors and found that there are inadequate control measures to prevent this event. For instance, vincristine is prepared in small volume syringes which could be confused for intrathecal use; vincristine and intrathecal medications are prescribed and administered on the same day; vincristine and intrathecal medications are stored in the same refrigerators and there is a lack of adequate warning labels on the syringe. The team recommended that vincristine be diluted in minibags using Sodium chloride $(20 \mathrm{ml}$ for paediatrics and $50 \mathrm{ml}$ for adults). Scheduled administration of intravenous drugs should be different from intrathecal drugs, with intravenous drugs administered first. Adequate labelling of the medication including warning labels and proper sensitization of staff on proper handling of cytotoxics were also recommended.

\section{DISCUSSION}

We used HFMEA to evaluate the vincristine use process aiming to improve the chemotherapy use process in both adult and paediatric oncology units in KNH. The HFMEA team found that the medication-use processes were complex, that processes were carried out by different cadres of health professionals with different levels of expertise, and that these processes were prone to many failure modes. The analysis enhanced the teams' understanding of the various vulnerabilities and strengths in the chemotherapy use process. The detailed-nature of the HFMEA process highlighted risks that could be reduced easily as well as complex ones that required organizational approach.

The 12 failure modes and causes were subsequently identified not to have adequate preventive measures in place to curb against their occurrences after a thorough analysis of the initial 77 failure modes. The HFMEA team reviewed the literature and expert opinions to identify potential activities aimed at preventing the occurrence of high risk failure modes $(8,21-23,29,37)$. The members were cognizant of the fact that $\mathrm{KNH}$ is a resource-limited health facility in a LMIC in their rationalization of proposed activities. In almost all the 12 failure mode causes, members listed more than one specific mitigation strategies to ensure that the failure mode cause is adequately countered. The majority of identified recommendations were seen as simple, quick and in-expensive to implement such as the dilution of vincristine in large volume syringes and double-checks of doses in wards and pharmacy. However, some long-term initiatives were also recommended such as the amendment of the chemotherapy chart to provide for space for twice monthly charting of patients' weight and height and adoption of CPOE in chemotherapy prescribing. These are now being enacted. A number of the identified modes were similar to the earlier study of Tilburg et al including old treatment charts in the schedule, dose miscalculations and extravasation (30). However, some were different in our study including medication orders obscured, incomplete labelling and spillage (Table 2).

Overall, the HFMEA process brought forth substantial group and individual benefits to the team members. The HFMEA provided members with an opportunity for continuous professional development as it is a rich learning experience. Greater importance of teamwork was also elicited during this process as members appreciated the important roles that different cadres play in the 
chemotherapy use process. The team members had to also factor in different beliefs and ideas about the chemotherapy use process from members where some worked together but their beliefs were diverse to arrive at a consensus going forward. The HFMEA team generally found the process worthwhile, and recommended this for other situations in the hospital and wider to improve future patient care.

A detailed step by step description of vincristine use process was an additional valuable output of this process. This enabled members to audit and understand the sub-processes that they are involved in routinely. Overall, we believe the resultant process flow map can be used for audit and training purpose in this hospital and wider in Kenya as well as other similar LMICs experiencing problems with the administration of vincristine, with pharmacists playing a key role. The recommendations from this HFMEA are also expected to have a favourable effect on a large number of other medication use processes in $\mathrm{KNH}$ and wider in Kenya. Table 3 summarises the remedial activities for the high risk failure modes identified.

Since the completion of this study, the findings have been forwarded to KNH Research and Programs Department - a body mandated policy decisions and implementation. The Oncology pharmacy has already started adopting some of the recommendations made. These include the sensitization of staff on vincristine dosage, medication errors and adverse events. A proposal for recruitment of oncology pharmacists has also been presented to the hospital management alongside procurement process for pertinent equipment to be used for the preparation of cytotoxics. As a result, a biological safety cabinet has now been installed in the hospital. Training on the safe handling of cytotoxics has also been carried out and the use of chemo-ports for children has been initiated.

Since January 2019, a paediatric chemotherapy roadmap/protocol has been implemented for children being treated for malignancies in $\mathrm{KNH}$. The roadmap is now in all paediatric files and a copy in the pharmacy. It is envisaged this will aid in minimising dosing errors and enhance the administration of correct regimens, and this is being followed up. A procurement proposal for a label's printer, labels and spill kits was presented to the hospital management by November 2018, and is being enacted. A planned meeting to discuss the study results to $\mathrm{KNH}$ Journal club has also taken place to further improve the administration of vincristine in the hospital, and we will be monitoring these developments in the future. The pharmacy department has also been tasked in the 2018/2019 financial year target to develop an implementation plan for all recommendations from studies undertaken within the past one year. As a result, a study is currently being undertaken to determine the prevalence of vincristine medication errors after the implementation of the recommendations as the baseline prevalence study has already been undertaken by Kurgat et al (17). This will be reported in the future.

Study Limitations

HFMEA does not measure the actual failure rates or medication error rates. The determination of outcomes where there are no incidence reports is also a challenge. However for this study, outcomes for prescribing process (medication error prevalence of $98.8 \%$ ) were available while other processes were estimated based on experience and a sense of what happens in $\mathrm{KNH}$. HFMEA team members were expected to have biased personal opinions depending on the unit they work; however, this was minimised by having a multidisciplinary team. Overall, we believe our processes were robust providing direction for the future.

\section{CONCLUSION}

Multiple medication errors can occur at each stage of the chemotherapy use process making it a highrisk process. These errors can have serious consequences. HFMEA is a useful tool to identify improvements to medication safety and reduce patient harm in all countries including LMICs. The HFMEA process driven by pharmacists also brings together the multidisciplinary team involved in patient care to identifying potential failure modes, who subsequently own the recommendations made, enhancing the chances of implementation. The impact of the suggestions in $\mathrm{KNH}$ made will be monitored, with further measures introduced if necessary to reduce concerns with the administration of vincristine in the hospital. It is envisaged that the findings with be of interest to other hospitals in Kenya administering vincristine as well as other LMICs.

\section{Availability of data and materials}

The datasets used and/or analysed during the current study are available on reasonable request.

\section{Competing interests}

The Authors declare no conflicts of interest. 


\section{Funding}

No funding - Self-Sponsored Study

\section{Acknowledgments}

We acknowledge all the members of the HFMEA multidisciplinary team and staff of Kenyatta National Hospital oncology unit who helped contribute to this study.

\section{Authors Contributions}

- Design and Conception: EKK, ANG, IW, DW

- Data collection: EKK

- Data analysis and interpretation: EKK, ANG, IW, DW, BBG

- Manuscript writing: EKK, ANG, IW, DW, BBG, AK 
Table 1: Hazard Scoring Matrix

\begin{tabular}{|c|c|c|c|c|}
\hline \multirow{2}{*}{$\begin{array}{l}\text { 프 } \\
\overline{0} \\
\frac{0}{0} \\
\frac{0}{0} \\
\vdots\end{array}$} & \multicolumn{4}{|c|}{ Severity of effect } \\
\hline & Catastrophic & Major & Moderate & Minor \\
\hline Frequent & 16 & 12 & 8 & 4 \\
\hline Occasional & 12 & 8 & 6 & 3 \\
\hline Uncommon & 8 & 4 & 4 & 2 \\
\hline Remote & 4 & 3 & 2 & 1 \\
\hline
\end{tabular}

Table 3: Summary of Remedial Strategies for High risk Failure Modes

Recommendations
Prescribing
- Amendment of the chemotherapy chart to provide for space for twice monthly charting of the patient weight
and height.
- Update prescribers on the difference between the schedule day and Date of administration
- Redesign the Chemotherapy treatment chart to provide adequate space to affix the date of administration
- Revelop job aids for calculations of BSA, dosages and determine minimum and maximum doses
- Sensitize prescribers on non-standard abbreviations to avoid.
- Adopt the use of Computerised Physician Order Entry System in chemotherapy prescribing
- Dose calculation double-check

\section{Preparation and Dispensing}

- Design and print (purple) Colour-coded labels with Predesigned Warnings (BOLD) and Route of Administration. Name and IP/OP No. space provided

- Develop clear policy guidelines on what to affix on the label and disseminate to staff in the unit

- Design a clear warning label and affix on the syringe (INTRAVENOUS USE ONLY, FATAL IF ADMINISTERED VIA OTHER ROUTES)

- Sensitize staff on the necessity of affixing warning labels

- Ensure all areas where production, storage and administration of cytotoxics have spill kits

- Centralize production of cytotoxics at the pharmacy to be done exclusively by pharmacy staff

- Sensitize staff on how to handle cytotoxics especially new Senior house officers

\section{Administration and Monitoring}

- Enforce training and education to ensure Independent double checks are done by a Nurse or by two Senior house officers before administration at bedside

- Ensure at least 2 staff perform medication administration 
- Provision of extravasation kits

- Staff training on prevention of extravasation

- Ensure administration is by slow IV for at least 2 minutes and flush with $10 \mathrm{ML}$ of Normal saline after administration

- Dilute vincristine to $10 \mathrm{ML}$ volume for $<10$ years patients and $20 \mathrm{ML}$ for $>10$ years using Sodium Chloride $0.9 \%$ or 20ML Minibags for paeds and 50ML minibags for adults

- Prescribe vincristine and other intravenous drugs to be administered on a different day or time from Intrathecal medications. Intravenous medications be administered first

- Vincristine and Intrathecal preparations should be packaged separately in colour-coded adequately labelled plastic bags. They should also be stored in separate refrigerators.

- Chemotherapy administration be done strictly on weekdays between 8:30 AM and 5:00 PM

- Enforce training on the importance of post-administration monitoring and ensure medication administration is done by at least 2 officers 
Table 2: Vincristine use process Failure Modes and Recommendations

\begin{tabular}{|c|c|c|c|c|c|c|c|}
\hline \multirow[b]{2}{*}{$\begin{array}{l}\text { First Evaluate failure mode before } \\
\text { determining potential causes }\end{array}$} & \multirow[b]{2}{*}{ POTENTIAL CAUSE } & \multicolumn{3}{|c|}{ SCORING } & \multicolumn{3}{|r|}{ DECISION TREE ANALYSIS } \\
\hline & & & & & 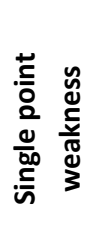 & 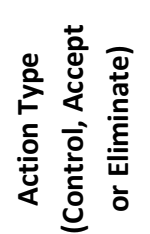 & Recommendations \\
\hline \multirow[t]{3}{*}{$\begin{array}{l}\text { 1. Out-dated patient height and weight measures } \\
\text { indicated }\end{array}$} & & 3 & 3 & 9 & & & \\
\hline & 1. Poor documentation & 3 & 3 & 9 & & Control & $\begin{array}{l}\text { Twice monthly charting of weight and Height be documented on the } \\
\text { Treatment sheet/Chemotherapy chart }\end{array}$ \\
\hline & 2. Lack of space to fix latest measures & 3 & 4 & 12 & & Control & $\begin{array}{l}\text { Amend the Chemotherapy chart to provide for the provision of twice } \\
\text { monthly charting of weight and height }\end{array}$ \\
\hline \multirow[t]{3}{*}{$\begin{array}{l}\text { 2. Previous history inconclusive in determining last } \\
\text { date of Vincristine administration }\end{array}$} & & 3 & 3 & 9 & & & \\
\hline & $\begin{array}{l}\text { 1. Misinterpretation between schedule } \\
\text { day and date of administration }\end{array}$ & 3 & 3 & 9 & & Control & $\begin{array}{l}\text { Update prescribers on the difference between the schedule day and } \\
\text { Date of administration }\end{array}$ \\
\hline & $\begin{array}{l}\text { 2. Inadequate space to affix the date } \\
\text { on the Treatment sheet }\end{array}$ & 3 & 4 & 12 & & Eliminate & $\begin{array}{l}\text { Redesign the Chemotherapy treatment chart to provide adequate space } \\
\text { to affix the date }\end{array}$ \\
\hline \multirow[t]{3}{*}{ 3. Dose miscalculation } & & 4 & 3 & 12 & & & Ensure double-checks in wards and pharmacy. \\
\hline & $\begin{array}{l}\text { 1. Non-adherence to treatment } \\
\text { protocol }\end{array}$ & 3 & 3 & 9 & & Control & $\begin{array}{l}\text { Develop job aids for calculations of BSA, dosages and determine } \\
\text { minimum and maximum doses }\end{array}$ \\
\hline & 2. Use of inaccurate BSA & 4 & 3 & 12 & & Control & $\begin{array}{l}\text { Amend the Chemotherapy chart to provide for the provision of twice } \\
\text { monthly charting of weight and height }\end{array}$ \\
\hline
\end{tabular}




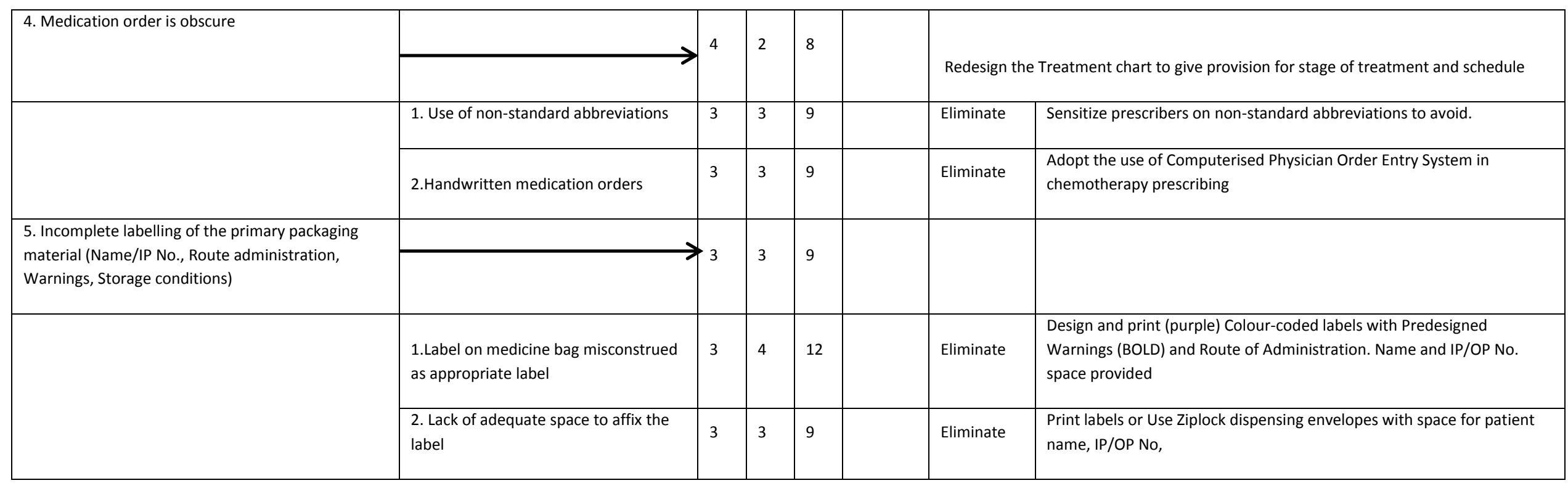




\begin{tabular}{|c|c|c|c|c|c|c|c|}
\hline \multirow[b]{2}{*}{ First Evaluate failure mode before determining potential causes } & \multirow[b]{2}{*}{ POTENTIAL CAUSE } & \multicolumn{3}{|c|}{ SCORING } & \multicolumn{3}{|r|}{ DECISION TREE ANALYSIS } \\
\hline & & & & & 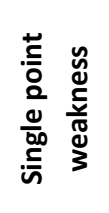 & 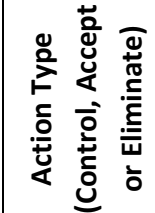 & Recommendations \\
\hline \multirow[t]{3}{*}{$\begin{array}{l}\text { 6. Incomplete label affixed on the syringe((Name, IP/OP No, Preparation } \\
\text { date, Expiry date, Medication name, dose and route of administration) }\end{array}$} & & 3 & 4 & 12 & & \multicolumn{2}{|c|}{$\begin{array}{l}\text { Print label and affix on plastic Ziplock bag/ Purchase infusion minibags or use large } \\
\text { volume syringes }>20 \mathrm{cc}\end{array}$} \\
\hline & $\begin{array}{l}\text { 1. Lack of clear guidelines on } \\
\text { what to affix on the label }\end{array}$ & 3 & 4 & 12 & & Control & $\begin{array}{l}\text { Develop clear policy guidelines on what to affix on the label and } \\
\text { disseminate to staff in the unit }\end{array}$ \\
\hline & $\begin{array}{l}\text { 2. Lack of adequate space to } \\
\text { affix the label }\end{array}$ & 3 & 3 & 9 & & Control & $\begin{array}{l}\text { Design colour-coded label, purchase labels printer and print with } \\
\text { required items( (Name, IP/OP No, Preparation date, Expiry date, } \\
\text { Medication name, dose and route of administration) }\end{array}$ \\
\hline \multirow[t]{3}{*}{$\begin{array}{l}\text { 7. Failure to affix WARNING label (INTRAVENOUS USE ONLY, FATAL IF } \\
\text { ADMINISTERED VIA OTHER ROUTES) }\end{array}$} & & 2 & 4 & 8 & & & \\
\hline & 1.Lack of clear guidelines/SOP & 2 & 4 & 8 & & Eliminate & $\begin{array}{l}\text { Design a clear warning label and affix on the syringe (INTRAVENOUS } \\
\text { USE ONLY, FATAL IF ADMINISTERED VIA OTHER ROUTES) }\end{array}$ \\
\hline & $\begin{array}{l}\text { 2.Lack of awareness on what to } \\
\text { affix on the label }\end{array}$ & 2 & 4 & 8 & & Control & Sensitize staff on the necessity of affixing warning labels \\
\hline \multirow[t]{4}{*}{ 8. Medication spillage } & & 4 & 2 & 8 & & & \\
\hline & $\begin{array}{l}\text { 1. Lack of adequate working } \\
\text { space }\end{array}$ & 4 & 2 & 8 & & Accept & $\begin{array}{l}\text { Ensure all areas where production, storage and administration of } \\
\text { cytotoxics have spill kits }\end{array}$ \\
\hline & $\begin{array}{l}\text { 2. Production in an } \\
\text { inappropriate environment }\end{array}$ & 4 & 2 & 8 & & Control & $\begin{array}{l}\text { Centralize production of cytotoxics at the pharmacy to be done } \\
\text { exclusively by pharmacy staff }\end{array}$ \\
\hline & 3. Poor handling of cytotoxics & 4 & 2 & 8 & & Control & $\begin{array}{l}\text { Sensitize staff on how to handle cytotoxics especially new Senior house } \\
\text { officers }\end{array}$ \\
\hline $\begin{array}{l}\text { 9. Failure to adequately confirm vital information before administration } \\
\left.\text { ( } 7 R^{\prime} s\right)\end{array}$ & & 4 & 1 & 4 & YES & \multicolumn{2}{|c|}{$\begin{array}{l}\text { Enforce training and education to ensure Independent double checks are done by a } \\
\text { Nurse or by two Senior house officers before administration at bedside }\end{array}$} \\
\hline
\end{tabular}




\begin{tabular}{|c|c|c|c|c|c|c|c|}
\hline & 1. Heavy workload & 4 & 1 & 4 & YES & Accept & Ensure at least 2 staff perform medication administration \\
\hline \multirow[t]{4}{*}{ 10a. Vincristine leaks to adjacent tissues(extravasation) } & & 4 & 3 & 12 & & & Provision of extravasation kits \\
\hline & $\begin{array}{l}\text { 1. IV line fixed adjacent to } \\
\text { recently used venipuncture }\end{array}$ & 4 & 3 & 12 & & Control & Staff training on prevention of extravasation \\
\hline & 2. Improper administration rate & 4 & 3 & 12 & & Control & $\begin{array}{l}\text { Ensure administration is by slow IV for at least } 2 \text { minutes and flush with } \\
10 \mathrm{MI} \text { of Normal saline after administration }\end{array}$ \\
\hline & 4.Nonadherance to guidelines & 4 & 2 & 8 & & Control & $\begin{array}{l}\text { Sensitize staff on the guidelines on prevention of extravasation. Dilute } \\
\text { vincristine to } 10 \mathrm{ml} \text { volume for }<10 \text { years patients and } 20 \mathrm{ml} \text { for }>10 \\
\text { years using Normal saline }\end{array}$ \\
\hline
\end{tabular}

\begin{tabular}{|c|c|c|c|c|c|c|}
\hline \multirow[t]{3}{*}{ 10b.The doctors fails to notice exosmosis has occurred } & & 4 & 2 & 8 & \multicolumn{2}{|c|}{$\begin{array}{l}\text { All units should have (Fully Kitted) extravasation kits. Chemotherapy administration } \\
\text { be done strictly on weekdays between 8:30 AM and 5:00 PM }\end{array}$} \\
\hline & $\begin{array}{l}\text { 1. The doctor was in a hurry } \\
\text { due to heavy workload thus } \\
\text { patient monitoring wasn't } \\
\text { done after administration }\end{array}$ & 4 & 2 & 8 & Accept & $\begin{array}{l}\text { Enforce training on the importance of post-administration monitoring } \\
\text { and ensure medication administration is done by at least } 2 \text { officers }\end{array}$ \\
\hline & $\begin{array}{l}\text { 2. The patient turned around in } \\
\text { bed }\end{array}$ & 4 & 2 & 8 & Accept & Ensure that the patient remains in bed still after administration \\
\hline
\end{tabular}




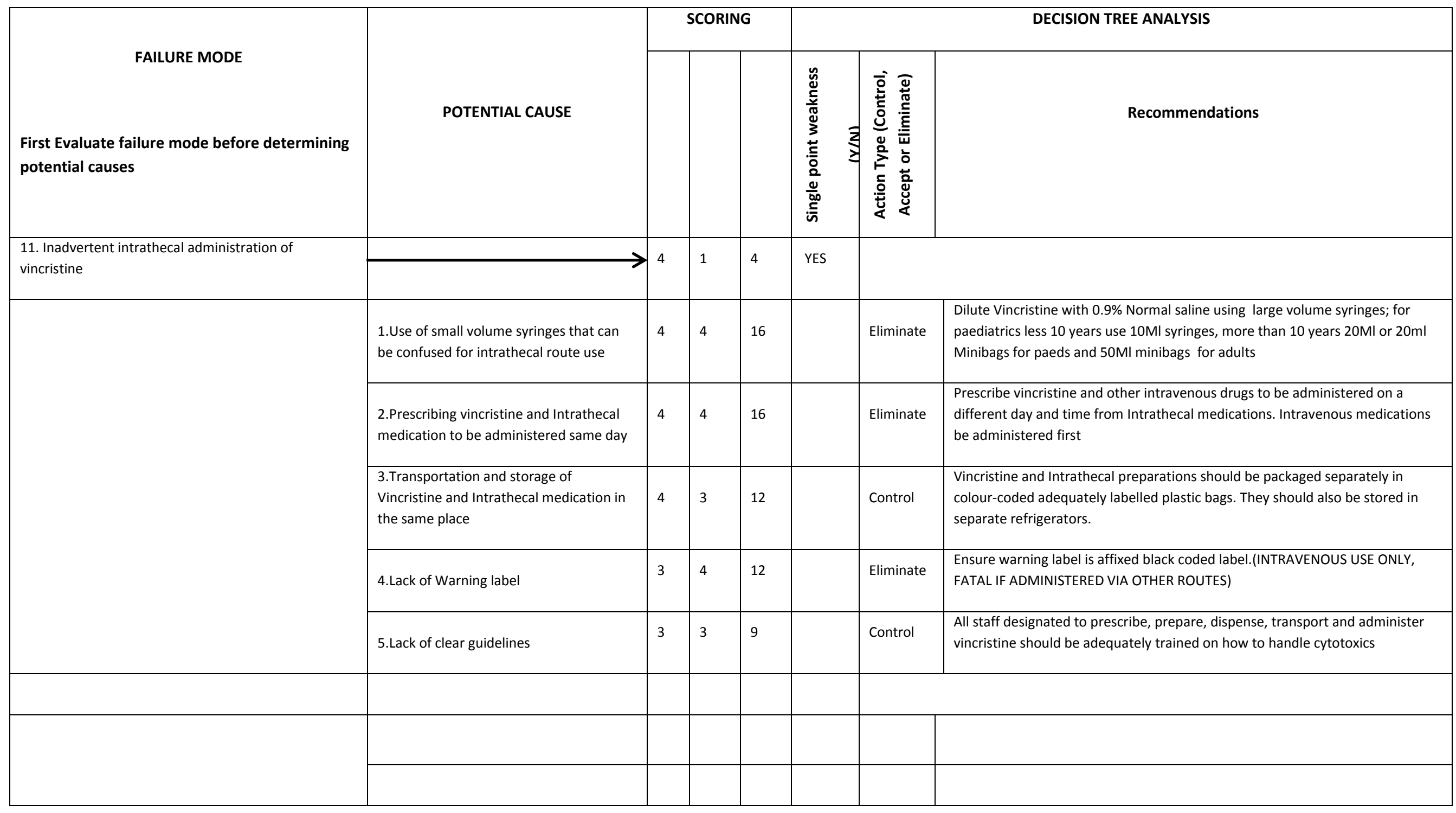




\section{Box 1 - Steps in HFMEA Procedure}

\section{- Define the HFMEA topic}

\section{- Assemble Team}

- Graphically describe the process:

- Set up a flow diagram

- Consecutively number each process step

- If the process is complex, identify the area of process to focus on

- Identify and consecutively number all sub-process steps

- Create a process flow diagram.

\section{- Hazard Analysis:}

- List and consecutively number all potential failure modes for each process

- Determine the severity and probability of potential failure modes and determine hazard score using hazard scoring matrix (Table 1)

- Use decision tree to determine whether the failure mode warrants further action

- List all failure mode causes for each failure mode which warrants further action

- Identifying mitigation strategies:

- Decide whether to "Eliminate", "control" or "Accept" failure mode causes

- Describe an action for each failure mode cause that will eliminate or control it

- Identify outcome measure

- Identify a single individual to complete the recommended action

- Indicate whether top management has concurred with the recommended actions 
Figure 1: HFMEA Process Flow Diagram

\begin{tabular}{|c|c|}
\hline Prescription & Preparation and dispensing \\
\hline $\begin{array}{l}\text { Sub-Processes } \\
\text { A. Checking patient's medical record } \\
\text { a. Diagnosis type of malignancy and staging } \\
\text { b. Hypersensitivity history } \\
\text { c. Co-morbidities and contraindications } \\
\text { d. Chemotherapy schedule } \\
\text { e. Relevant laboratory results } \\
\text { B. Patient routine assessment } \\
\text { a. Ordering appropriate tests } \\
\text { b. Sample collection } \\
\text { C. Dosing } \\
\text { a. Measuring height and weight } \\
\text { b. Calculating Body surface area } \\
\text { c. Dose calculation } \\
\text { D. Prescription Detailing } \\
\text { a. Patient biodata (Name, age, sex, } \\
\text { weight, height, IP/OP No., BSA) } \\
\text { b. Diagnosis, staging and regimen } \\
\text { c. Date of prescription and cycle number } \\
\text { d. Drugs to be given(generic name(FULL), } \\
\text { dose, route (FULL), frequency and duration } \\
\text { of duration of administration) } \\
\text { e. Days, dates when each drug is to be given } \\
\text { f. The prescriber's name, designation and } \\
\text { signature } \\
\text { E. Medication order sent to Pharmacy } \\
\text { a. Prescription duplicated into Non- } \\
\text { Schedule form and S11 } \\
\text { b. Medication order and patient file taken to } \\
\text { pharmacy }\end{array}$ & $\begin{array}{l}\text { Sub-processes } \\
\text { A. Verifying the prescription } \\
\text { a. Checking for completeness } \\
\text { i. Patient's basic information (IP/OP number, date, doctor's information, } \\
\quad \text { medicine quantity) } \\
\text { ii. Checking administration information( date, medicine name, dosage, } \\
\quad \text { days and frequency) } \\
\text { B. Prescription Validation } \\
\text { a. Checking for protocol adherence } \\
\text { b. Confirm test results are optimal } \\
\text { c. Dose Re-calculation } \\
\text { d. Checking drug interactions, side effects profile and hypersensitivity } \\
\text { e. Authorization by Oncology pharmacist } \\
\text { C. Medicine Retrieval } \\
\text { a. Control on the S11 } \\
\text { b. Charge, issue and record in the HMIS } \\
\text { c. Checking for medicine availability } \\
\text { d. Medicine retrieval } \\
\text { e. Labelling of medicine bag } \\
\text { f. Labelling of the medication } \\
\text { g. Packing the medicine in a medicine bag } \\
\text { h. Transportation to the Chemotherapy preparation room } \\
\text { D. Medicine Preparation } \\
\text { a. Staff don Personal protective equipment } \\
\text { b. Checking if the patient identifiers(name, IP/OP No.), prescription, medicine, and } \\
\text { label correspond with the original prescription } \\
\text { c. Confirming the dosage, volume, and administration date } \\
\text { d. Checking that medicine in vial is clear and without any foreign matter } \\
\text { e. Syringe selection } \\
\text { f. Drawing the medicine into a syringe } \\
\text { g. Labelling of the syringe } \\
\text { E. Packing the medicine } \\
\text { a. Packing the medicine into a medicine bag } \\
\text { b. Sealing the medicine bag } \\
\text { c. Filling the S11 } \\
\text { d. Calling for transport } \\
\text { a }\end{array}$ \\
\hline
\end{tabular}

\section{3}

\begin{tabular}{l}
\hline Transportation \\
\hline Sub-processes \\
A. $\quad$ Calling for transport \\
B. $\quad$ Receiving the medicine \\
- $\quad$ Confirming the medication \\
- $\quad$ Signing for the medicine \\
C. Transport
\end{tabular}

\section{4} Storage

Sub-processes

A. Storage in the
refrigerator
- Sorting the drugs
- Arranging the drugs

\section{5}

Administration

Sub-processes

A. Patient Preparation

a. Explaining to the patient the administration procedure and seeking informed consent

b. Review recent blood tests results and Record baseline vital signs

c. Cleaning injection site and fixing IV line

B. Assembling Medicine and Materials

a. The Nurse ensure the required items are prepared and availed

b. Staff don Protective devices(PPEs)

C. Medicine Re-confirmation

a. Medical officer call the patient by name

b. Two MOs checks the medicine against patient ID( 7R's)

c. The Iv line is primed

D. Medicine Administration
a. Administration by slow Iv Push
b. Remove the syringe
c. Flush IV line with Normal saline
d. Hydrate the patient
e. Document date of administration and comments on the medication chart and notes

E. Monitoring

a. Check skin around IV access

b. Monitor patient general wellbeing 


\section{References}

1. Cheng $\mathrm{CH}$, Chou CJ, Wang PC, Lin HY, Kao CL, Su CT. Applying HFMEA to prevent chemotherapy errors. Journal of medical systems. 2012;36(3):1543-51.

2. Dhamija M, Kapoor G, Juneja A. Infusional chemotherapy and medication errors in a tertiary care pediatric cancer unit in a resource-limited setting. Journal of pediatric hematology/oncology. 2014;36(7):e412-5.

3. National Coordinating Council for Medication Error Reporting and Prevention. What is a Medication Error? 2016. Available from: http://www.nccmerp.org/about-medication-errors.

4. Maaskant JM, Vermeulen H, Apampa B, Fernando B, Ghaleb MA, Neubert A, et al. Interventions for reducing medication errors in children in hospital. The Cochrane database of systematic reviews. 2015(3):Cd006208.

5. Institute of Medicine Committee on Quality of Health Care in A. In: Kohn LT, Corrigan JM, Donaldson MS, editors. To Err is Human: Building a Safer Health System. Washington (DC): National Academies Press (US). Copyright 2000 by the National Academy of Sciences. All rights reserved.; 2000.

6. Choi I, Lee SM, Flynn L, Kim CM, Lee S, Kim NK, et al. Incidence and treatment costs attributable to medication errors in hospitalized patients. Research in social \& administrative pharmacy. 2016;12(3):428-37.

7. Phillips J, Beam S, Brinker A, Holquist C, Honig P, Lee LY, et al. Retrospective analysis of mortalities associated with medication errors. American journal of health-system pharmacy. 2001;58(19):1835-41.

8. The Society of Hospital Pharmacists of Australia. High-risk medication alert for vincristine injection. 2005. Available at URL: https://www.safetyandquality.gov.au/wp-

content/uploads/2012/02/vlitera2.pdf.

9. Serrano-Fabia A, Albert-Mari A, Almenar-Cubells D, Jimenez-Torres NV. Multidisciplinary system for detecting medication errors in antineoplastic chemotherapy. Journal of oncology pharmacy practice. 2010;16(2):105-12.

10. ISMP. Institute for Safe Medication Practices. ISMPs list of High Alert Medications. 2012.

Available at URL: https://www.ismp.org/recommendations/high-alert-medications-acute-list.

11. Torre LA, Bray F, Siegel RL, Ferlay J, Lortet-Tieulent J, Jemal A. Global cancer statistics, 2012. CA. 2015;65(2):87-108.

12. IARC. World Cancer Report 2014. Editors BW Stewart and CP Wild. Available at URL: http://www.searo.who.int/publications/bookstore/documents/9283204298/en/.

13. Chalkidou K, Marquez P, Dhillon PK, Teerawattananon Y, Anothaisintawee T, Gadelha CA, et al. Evidence-informed frameworks for cost-effective cancer care and prevention in low, middle, and high-income countries. The Lancet Oncology. 2014;15(3):e119-31.

14. KNCO. Kenya Cancer Statistics \& National Strategies. Available at URL:

https://kenyacancernetwork.wordpress.com/kenya-cancer-facts/.

15. Atieno OM, Opanga S, Martin A, Kurdi A, Godman B. Pilot study assessing the direct medical cost of treating patients with cancer in Kenya; findings and implications for the future. Journal of medical economics. 2018;21(9):878-87.

16. Ministry of Health (Kenya). National Guidelines for Cancer Management Kenya. August 2013. Available at URL: http://kehpca.org/wp-content/uploads/National-Cancer-Treatment-Guidelines2.pdf.

17. Kurgat E, Guantai A, Weru I, Wata D. Assessment of vincristine medication errors and contributing factors in Kenyatta National Hospital, Kenya. J Oncol Pharm Pract. 2018;24(4

(Supplement)):15-6. Available at URL:

https://journals.sagepub.com/doi/pdf/10.1177/1078155218761020.

18. NSW Government. Policy Directive. High-Risk Medicines Management Policy. 2015.

Available at URL: https://www1.health.nsw.gov.au/pds/ActivePDSDocuments/PD2015 029.pdf.

19. Government of Western Australia. WA High Risk Medication Policy. Office of Patient Safety and Clinical Quality. 2014. Available at URL:

https://ww2.health.wa.gov.au/ /media/Files/Corporate/Policy\%20Frameworks/Unallocated/Policy/WA \%20High\%20Risk\%20Medication\%20Policy/Supporting/WA-High-Risk-Medication-Policy.pdf.

20. Müller T. Typical Medication Errors in Oncology: Analysis and Prevention Strategies. Oncol Reasearch Treat. 2003;26(6):539-544. Available from: http://www.karger.com/Article/Abstract/74148. 21. Graham S, Clopp MP, Kostek NE, Crawford B. Implementation of a high-alert medication program. The Permanente journal. 2008;12(2):15-22. 
22. Gilbar P, Chambers CR, Larizza M. Medication safety and the administration of intravenous vincristine: international survey of oncology pharmacists. Journal of oncology pharmacy practice. 2015;21(1):10-8.

23. Saedder EA, Brock B, Nielsen LP, Bonnerup DK, Lisby M. Identifying high-risk medication: a systematic literature review. European journal of clinical pharmacology. 2014;70(6):637-45.

24. Ranchon F, Moch C, You B, Salles G, Schwiertz V, Vantard N, et al. Predictors of prescription errors involving anticancer chemotherapy agents. Eur J Cancer. 2012;48(8):1192-9.

25. Franklin BD, Panesar SS, Vincent C, Donaldson LJ. Identifying systems failures in the pathway to a catastrophic event: an analysis of national incident report data relating to vinca alkaloids. BMJ quality \& safety. 2014;23(9):765-72.

26. Australian Council for Safety and Quality in Health Care. MEDICATION ALERT! VINCRISTINE can be fatal if administered by the intrathecal route. 2005. Available at URL: https://www.safetyandquality.gov.au/wp-content/uploads/2012/01/valert.pdf.

27. Fyhr AS. Risks in the chemotherapy process and possibilities for improvement. Licentiate Thesis. 2011. Available at URL: http://www.eat.Ith.se/fileadmin/eat/AnnSofie Fyhr HELA.pdf. 28. Bonnabry P, Cingria L, Ackermann M, Sadeghipour F, Bigler L, Mach N. Use of a prospective risk analysis method to improve the safety of the cancer chemotherapy process. International journal for quality in health care. 2006;18(1):9-16.

29. Schulmeister L. Preventing vincristine sulfate medication errors. Oncology nursing forum. 2004;31(5):E90-8.

30. van Tilburg CM, Leistikow IP, Rademaker CM, Bierings MB, van Dijk AT. Health Care Failure Mode and Effect Analysis: a useful proactive risk analysis in a pediatric oncology ward. Quality \& safety in health care. 2006;15(1):58-63.

31. DeRosier J, Stalhandske E, Bagian JP, Nudell T. Using health care Failure Mode and Effect Analysis: the VA National Center for Patient Safety's prospective risk analysis system. The Joint Commission journal on quality improvement. 2002;28(5):248-67, 09.

32. Teoh PC, Case K. An evaluation of failure modes and effects analysis generation method for conceptual design. International Journal of Computer Integrated Manufacturing. 2005;18(4):279-93.

33. Asgari Dastjerdi H, Khorasani E, Yarmohammadian MH, Ahmadzade MS. Evaluating the application of failure mode and effects analysis technique in hospital wards: a systematic review. Journal of injury \& violence research. 2017;9(1).

34. Ashley L, Dexter R, Marshall F, McKenzie B, Ryan M, Armitage G. Improving the safety of chemotherapy administration: an oncology nurse-led failure mode and effects analysis. Oncology nursing forum. 2011;38(6):E436-44.

35. The Joint Commission. Failure Mode and Effects Analysis in Health Care: Proactive Risk Reduction. 3rd ed. Ulaskas C, Westergaard F, Reis P, editors. Illinois; 2010. Available at URL: http://www.jcrinc.com/assets/1/14/FMEA10 Sample Pages.pdf.

36. Mwanda WO. Kasili's Synopsis of the Management of Paediatric Cancers in Kenya. Nairobi: $\mathrm{KNH} ; 2012$.

37. World Health Organization. Information Exchange System Alert No. 115. Geneva; 2007. Available from: http://www.who.int/medicines/publications/drugalerts/Alert 115 vincristine.pdf. 